\title{
Reliability of Concrete Elements Designed for Alternative Load Combinations Provided in Eurocodes
}

\author{
M. Holický, J. Marková
}

The basic European standard for design of buildings and other engineering works, EN 1990 "Basis of structural design", provides alternative design procedures, for which national choice is allowed. One of the most important questions concerns three fundamental combinations of actions for persistent and transient design situations in the Ultimate limit states. Simple examples of reinforced concrete elements show, that the alternative load combinations may lead to considerably different reliability levels. Probabilistic methods of structural reliability theory are used to identify characteristic features of each combination and to formulate recommendations. However, further calibration studies are urgently needed in order to prepare National annexes to EN 1990 on time.

Keywords: Eurocodes, combination of actions, partial factors, reinforced concrete beam, column, reliability index.

\section{Introduction}

The operational European standards for the design of structures, so called Eurocodes, are currently in an advanced stage of development. During the next few years, most European countries should be prepared to use newly developed harmonised standards for structural design. The original intention of the European Committee for Standardisation CEN that the design may differ in individual countries only in the numerical values of some parameters, such as partial factors and characteristic values of climatic actions, has not been fulfilled. Recently available documents show that the foreseen high level of harmonisation has not been reached, and that the national institutions will be free to choose not only the numerical values of the various reliability elements, but in some cases also one of the alternative design procedures.

Since April 2002, two basic documents EN 1990 [1] and EN 1991-1-1 [2] have been available. These two standards resulted from transformation of the relevant prestandards [3] and [4]. The final draft of the standard EN 1992-1-1 [5] for the design of concrete structures, which relates to the prestandard [6], is now also available. In the next two years, these transformed documents will be implemented in the Member States of CEN, together with the National annexes, as operational national standards. Existing valid standards, that are in contradiction with the CEN documents, will gradually be modified or withdrawn. This process will require important national decisions that should be based on well-prepared calibration.

The National annexes should include the recommendation of one of the alternatives indicated in EN 1990 for a fundamental combination of actions in the Ultimate limit states and partial factors $\gamma_{G}$ and $\gamma_{Q}$ for permanent and variable actions. It will be shown that the choice of these nationally determined parameters may significantly affect the resulting reliability level.

The reliability of two basic reinforced concrete elements, a beam and a column, are analysed taking into consideration alternative load combinations and possible variation of the partial factors $\gamma_{\mathrm{G}}$ and $\gamma_{\mathrm{Q}}$. In this way the presented study extends a previous similar study [7] that concerns structures made from different materials. However, contribution [7] is related to an earlier version of Eurocode ENV 1991-1 [3]. Additional updated reliability studies are therefore required [e.g., 8, 9] to develop comprehensive background materials enabling national decisions concerning load combinations and partial factors to be applied in accordance with the present version of EN 1990 [1].

\section{Fundamental load combination}

In the following analysis, the combination of three actions is considered: permanent action $G$, imposed load $Q$ (leading) and wind $W$ (accompanying). EN 1990 [1] for the fundamental combination of these loads in permanent and transient design situations introduces three alternative procedures denoted here A, B and C. Assuming linear behaviour of structural members, actions $G, Q$ and $W$ and their characteristic values $G_{k}, Q_{k}$ and $W_{k}$ denote generally appropriate load effects (not the original actions).

A. Considering the formula (6.10) in EN 1990 [1], the design value of action effect $E_{\mathrm{d}}$ is given as

$$
E_{\mathrm{d}}=\gamma_{G} G_{\mathrm{k}}+\gamma_{Q} Q_{\mathrm{k}}+\gamma_{W} \psi_{W} W_{\mathrm{k}} \text {. }
$$

B. An alternative procedure is provided in $\mathrm{EN} 1990$ [1] by twin expressions $(6.10 \mathrm{a})$ and $(6.10 \mathrm{~b})$

$$
\begin{aligned}
& E_{\mathrm{d}}=\gamma_{G} G_{\mathrm{k}}+\gamma_{Q} \psi_{Q} Q_{\mathrm{k}}+\gamma_{W} \psi_{W} W_{\mathrm{k}} \\
& E_{\mathrm{d}}=\xi \gamma_{G} G_{\mathrm{k}}+\gamma_{Q} Q_{\mathrm{k}}+\gamma_{W} \psi_{W} W_{\mathrm{k}} .
\end{aligned}
$$

The less favourable action effect from (2) and (3) should be considered.

C. In addition EN 1990 [1] allows further modification of alternative $\mathrm{B}$, simplifying equation (2) by considering permanent loads only, thus the load effect is then

$$
E_{\mathrm{d}}=\gamma_{G} G_{\mathrm{k}} \text {. }
$$


The less favourable action effect resulting from (3) and (4) is then considered. In addition to the combinations A, B, C provided in EN 1990 [1] (for recommended values $\gamma_{G}=1.35$, $\gamma_{Q}=1.5$ ) an additional combination $\mathrm{D}$ is also considered in the analysis as indicated in Figs. 1 and 3. The load combination D is the modified combination A (equation 6.10 in [1]) when reduced partial factors $\left(\gamma_{G}=1.2, \gamma_{Q}=1.4\right)$ recommended in the Czech implementation of ENV 1991-1 [3] are considered. This combination should illustrate the sensitivity of the resulting reliability level to partial factors, and the possible effect of reducing them.

If the leading action is wind $W$, then in equations (1) and (2) instead of reducing wind action $W$ by factor $\psi_{W}$, the imposed load $Q$ should be reduced by the appropriate factor $\psi_{Q}$. Factors $\gamma_{G}, \gamma_{Q}$ and $\gamma_{W}$ denote the partial factors of actions $G$, $Q$ and $W$ (the partial factors for both variable actions are equal, $\gamma_{Q}=\gamma_{W}$ ).

To investigate resulting load effects under various intensities of variable actions, the characteristic values of $G_{\mathrm{k}}$, $Q_{\mathrm{k}}$ and $W_{\mathrm{k}}$ are related using quantities $\chi$ given as the ratio of variable actions $Q_{\mathrm{k}}+W_{\mathrm{k}}$ to total load $G_{\mathrm{k}}+Q_{\mathrm{k}}+W_{\mathrm{k}}$, and ratio $k$ of accompanying action $W_{\mathrm{k}}$ to the main action $Q_{k}$

$$
\chi=\left(Q_{\mathrm{k}}+W_{\mathrm{k}}\right) /\left(G_{\mathrm{k}}+Q_{\mathrm{k}}+W_{\mathrm{k}}\right), k=W_{\mathrm{k}} / Q_{\mathrm{k}} .
$$

Note that a realistic range of $\chi$ is from 0.1 to 0.6 . However in some cases the load ratio $\chi$ may be very low if not zero (e.g. underground garages).

For a given design value of the load effect $E_{\mathrm{d}}$ the characteristic values of individual actions $G_{\mathrm{k}}, Q_{\mathrm{k}}, W_{\mathrm{k}}$ can be expressed using variables $\chi$ and $k$ as follows

$$
\begin{aligned}
G_{\mathrm{k}} & =\frac{E_{\mathrm{d}}}{(\xi) \gamma_{G}+\frac{\left(\left(\psi_{Q}\right) \gamma_{Q}+k\left(\psi_{W}\right) \gamma_{W}\right) \chi}{(1+k)(1-\chi)}}, \\
Q_{\mathrm{k}} & =\frac{\chi G_{\mathrm{k}}}{(1+k)(1-\chi)}, \\
W_{\mathrm{k}} & =k Q_{\mathrm{k}} .
\end{aligned}
$$

The factors $\xi, \gamma_{G}$ and $\gamma_{Q}$ indicated in the first relationship of $(6)$ in brackets are applied in the same way (either yes or no) as in equations (1) to (4) for alternative combination rules A, B and $\mathrm{C}$.

For alternative A, equation (1) is valid in the whole range $0 \leq \chi \leq 1$, whereas using alternative $B$, equation (2) is valid in the interval $0 \leq \chi \leq \chi_{\lim , \mathrm{B}}$ and equation (3) in the interval $\chi_{\lim , \mathrm{B}} \leq \chi \leq 1$. Correspondingly, for alternative $\mathrm{C}$ equation (4) is valid in the interval $0 \leq \chi \leq \chi_{\text {lim,C }}$ and equation (3) in the interval $\chi_{\lim , \mathrm{C}} \leq \chi \leq 1$. The limiting values $\chi_{\lim , \mathrm{B}}$ and $\chi_{\lim , \mathrm{C}}$ can be derived from equations (2) to (5) as follows

$$
\begin{aligned}
\chi_{\lim , \mathrm{B}} & =\frac{\gamma_{G}(1-\xi)(1+k)}{\gamma_{G}(1-\xi)(1+k)+\gamma_{Q}\left(a-\psi_{Q}\right)+\gamma_{W} k\left(b-\psi_{W}\right)} \\
\chi_{\lim , \mathrm{C}} & =\frac{\gamma_{G}(1-\xi)(1+k)}{\gamma_{G}(1-\xi)(1+k)+\gamma_{Q} a+\gamma_{W} k b},
\end{aligned}
$$

where the auxiliary variable $a=1$ and $b=\psi_{W}$ when for $k \leq\left(1-\psi_{Q}\right) /\left(1-\psi_{W}\right)$ (imposed load $Q$ is the leading action) and $a=\psi_{Q}$ and $b=1$ when $k<\left(1-\psi_{Q}\right) /\left(1-\psi_{W}\right)$ (action $W$ is the leading action).

\section{Resistance of reinforced concrete elements}

\subsection{Reinforced concrete beam}

The design value of flexural resistance $R_{\mathrm{d}}$ of the reinforced concrete beam is given as

$$
R_{\mathrm{d}}=\frac{A_{\mathrm{s}} f_{\mathrm{yk}}}{\gamma_{\mathrm{m}}}\left(h-d_{1}-0.5 A_{\mathrm{s}} \frac{\frac{f_{\mathrm{yk}}}{\gamma_{\mathrm{m}}}}{b \alpha \frac{f_{\mathrm{ck}}}{\gamma_{\mathrm{c}}}}\right) \text {, }
$$

where $A_{\mathrm{s}}$ denotes the area of reinforcement, $f_{\mathrm{yk}}$ and $f_{\mathrm{ck}}$ denote the characteristic strengths of reinforcement and concrete, $h$ is the height and $b$ is the width (considered here as a deterministic quantity equal to $0.3 \mathrm{~m}$ ) of the beam cross-section, $d_{1}$ axial distance of the bars to the beam bottom (considered here as a deterministic quantity equal to $0.03 \mathrm{~m}$ ), $\alpha$ the factor taking into account the long-term load effects on concrete compressive strength (considered here as a deterministic quantity equal to 1), $\gamma_{\mathrm{m}}$ and $\gamma_{\mathrm{c}}$ the partial factors for steel and concrete strength.

It is further assumed that the beam is designed (when usually height $h$ and reinforcement area $A_{\mathrm{s}}$ are specified) on the bases of so-called "economic design" when $R_{\mathrm{d}}=E_{\mathrm{d}}$ and no account is taken of the additional safety margin due to realistic dimensioning (which leads to the inequality $R_{\mathrm{d}}>E_{\mathrm{d}}$ ).

In the reliability analysis a structure is usually considered to be safe if resistance $R$ is greater than load effect $E$, both considered as random variables. Thus, when the limit state function (reliability margin) $g(\boldsymbol{X})=R-E$ is greater than $0, \boldsymbol{X}$ being the vector of basic variables. In the case of a beam the limit state function can be written as

$g(\boldsymbol{X})=K_{R} A_{\mathrm{s}} f_{\mathrm{y}}\left(h-d_{1}-0.5 \frac{A_{\mathrm{s}} f_{\mathrm{y}}}{b f_{\mathrm{c}}}\right)-K_{E}(G+Q+W)$,

where $K_{R}$ and $K_{E}$ are coefficients of model uncertainties for resistance $R$ and action effects $E$. Note that all variables in equation (10) are considered as random variables having a certain type of probability distribution.

\subsection{Reinforced concrete column}

The design value of resistance $R_{\mathrm{d}}$ for the short reinforced concrete column assuming very small (negligible) eccentricity and cross-sectional dimension $h \times b$ is given as

$$
R_{\mathrm{d}}=\frac{A_{\mathrm{s}} f_{\mathrm{yk}}}{\gamma_{\mathrm{m}}}+0.8 h b \frac{\alpha f_{\mathrm{ck}}}{\gamma_{\mathrm{c}}} .
$$

The column parameters are determined considering again the "economic design" when $R_{\mathrm{d}}=E_{\mathrm{d}}$.

In the case of the column the limit state function can be written as a condition given as

$g(X)=K_{R}\left(A_{\mathrm{s}} f_{\mathrm{y}}+0.8 h b f_{\mathrm{c}}\right)-K_{E}(G+Q+W)$,

where $K_{R}$ and $K_{E}$ are again coefficients of model uncertainties for variables $R$ and $E$. 


\section{Principles of reliability analysis}

The probability of failure $P_{\mathrm{f}}$ is the basic reliability measure used in this study. It can be expressed on the basis of a limit state (performance) function $\mathrm{g}(\boldsymbol{X})$ defined in such a way that a structure is considered to survive if $g(X)>0$ and to fail if $\mathrm{g}(\boldsymbol{X}) \leq 0$. An example of the function $g(X)$ is given by equations (10) and (12). In a general case failure probability $P_{\mathrm{f}}$ can be determined using the integral

$$
P_{\mathrm{f}}=\operatorname{Prob}(g(\boldsymbol{X}) \leq 0)=\int_{g(\boldsymbol{X}) \leq 0} \varphi_{\mathrm{g}}(\boldsymbol{X}) \mathrm{d} \boldsymbol{X},
$$

where $\varphi_{\mathrm{g}}(\boldsymbol{X})$ denotes the joint probability density distribution of the vector of basic variables $\boldsymbol{X}$, which may, however, not be available.

Assume that both the resistance $R(\boldsymbol{X})$ and the load effect $E(X)$ represent a single variable $Z$ used to analyse structural performance (e.g., axial force, bending moment or stress that is represented by $R(Z)$ and $E(Z)$ ). Then the integration indicated in expression (13) may be simplified and the probability $P_{\mathrm{f}}$ can then be expressed as:

$$
P_{\mathrm{f}}=\operatorname{Prob}(g(Z) \leq 0)=\int_{-\infty}^{\infty} \varphi_{E}(Z) \Phi_{R}(Z) \mathrm{d} Z,
$$

where $\varphi_{E}(Z)$ denotes the probability density function of $E(Z)$, $\Phi_{R}(Z)$ the distribution of $R(Z)$. To use equation (14) both the probability density function $\varphi_{E}(Z)$ and the distribution function $\Phi_{R}(Z)$ must be known (at least in an approximate form). A procedure based on expression (14) is used in this study.

Simplified, a time independent load model is accepted, using Turkstra's rule (the main action $G$ is described by an extreme value distribution for the considered design life of a structure, the accompanying wind load $W$ is approximated by the distribution of the annual extremes) is accepted. MathTable 2: Probabilistic models of basic variables cad and Matlab software products were used to develop the simple programs applied in the following analysis.

Note that there are commercially available software products (e.g., VaP [10], COMREL [11]), which can be used to determine the failure probability $P_{\mathrm{f}}$ in more complicated cases than those considered here (when expression (14) cannot be used). These software products were used in this study to check results obtained by numerical integration based on expression (14).

An alternative measure of reliability level is the reliability index $\beta$ (see Annex C of EN 1990 [1]), which is related to the probability of failure $P_{\mathrm{f}}$ as

$$
P_{f}=\Phi(-\beta)
$$

where $\Phi$ is the cumulative distribution function of the standardised normal distribution. The reliability index $\beta$ is frequently used, as its numerical values are more comfortable to handle than values of failure probability $P_{\mathrm{f}}$. The relationship between $P_{f}$ and $\beta$ is illustrated by the numerical values indicated in Table 1.

Table 1: Relation between $\beta$ and $P_{\mathrm{f}}$

\begin{tabular}{|l|l|l|l|l|l|l|l|}
\hline$P_{f}$ & $10^{-1}$ & $10^{-2}$ & $10^{-3}$ & $10^{-4}$ & $10^{-5}$ & $10^{-6}$ & $10^{-7}$ \\
\hline$\beta$ & 1.28 & 2.32 & 3.09 & 3.72 & 4.27 & 4.75 & 5.20 \\
\hline
\end{tabular}

EN 1990 [1] recommends for the Ultimate limit states of buildings designed for a fifty year period a target value of reliability index $\beta_{t}=3.8$ (for a one year period $\beta_{t}=4.7$ ), which corresponds to the probability of failure $P_{\mathrm{f}}=7.24 \cdot 10^{-5}$.

\section{Probabilistic models of basic variables}

As mentioned above in the reliability analysis all basic variables are considered as random variables having a certain

\begin{tabular}{|c|c|c|c|c|c|c|c|}
\hline $\begin{array}{c}\text { Type of } \\
\text { variable }\end{array}$ & $\begin{array}{c}\text { Symbol } \\
X\end{array}$ & Basic variable & Distr. & Units & Charact.value & $\mu$ & $\sigma$ \\
\hline \multirow[t]{4}{*}{ Action } & $G$ & Permanent action & $\mathrm{N}$ & $\mathrm{MN} / \mathrm{m}^{2}$ & $G_{\mathrm{k}}$ & $G_{\mathrm{k}}$ & $0.1 G_{k}$ \\
\hline & $Q$ & Imposed (50 years) & GUM & $\mathrm{MN} / \mathrm{m}^{2}$ & $Q_{k}$ & $0.6 Q_{\mathrm{k}}$ & $0.21 Q_{\mathrm{k}}$ \\
\hline & $W$ & Wind (1 year) & GUM & $\mathrm{MN} / \mathrm{m}^{2}$ & $W_{\mathrm{k}}$ & $0.3 W_{\mathrm{k}}$ & $0.15 W_{\mathrm{k}}$ \\
\hline & $W$ & Wind ( 50 years) & GUM & $\mathrm{MN} / \mathrm{m}^{2}$ & $W_{\mathrm{k}}$ & $0.7 W_{\mathrm{k}}$ & $0.245 W_{\mathrm{k}}$ \\
\hline \multirow{3}{*}{$\begin{array}{l}\text { Material } \\
\text { properties }\end{array}$} & $A_{\mathrm{s}}$ & Reinforc. area & DET & $\mathrm{m}^{2}$ & nom & nom & 0 \\
\hline & $f_{\mathrm{c}}$ & Concrete strength & $\mathrm{LN}$ & MPa & 20 & 28 & 4 \\
\hline & $f_{y}$ & Reinforc. strength & $\mathrm{LN}$ & MPa & 435 & 560 & 30 \\
\hline \multirow{3}{*}{$\begin{array}{l}\text { Geometric } \\
\text { data }\end{array}$} & $h$ & Beam height & $\mathrm{N}$ & $\mathrm{m}$ & 0.6 & 0.6 & 0.008 \\
\hline & $h, b$ & Column dimensions & $\mathrm{N}$ & $\mathrm{m}$ & 0.3 & 0.3 & 0.01 \\
\hline & $d_{1}$ & Reinforc. distance & GAM & $\mathrm{m}$ & 0.03 & 0.03 & 0.006 \\
\hline \multirow{2}{*}{$\begin{array}{l}\text { Model } \\
\text { uncertainties }\end{array}$} & $K_{E}$ & Load uncertainty & $\mathrm{LN}$ & - & 1.0 & 1.00 & 0.05 \\
\hline & $K_{R}$ & Resistance uncert. & $\mathrm{LN}$ & - & 1.0 & 1.10 & 0.15 \\
\hline
\end{tabular}
type of probability distribution. The probabilistic models of basic variables $X$ used in this study are summarized in Table 2. 
The models of basic variables indicated in Table 2 are chosen taking into account data provided by JCSS [12]. Note that the beam width $b=0.3 \mathrm{~m}$ and coefficient of long-term concrete strength $\alpha=1$ are considered as deterministic values.

\section{Results of reliability analysis}

The results of the reliability analysis, indicated by the reliability index $\beta$ (equation (14)) are shown in Figs. 1 and 2 for the reinforced concrete beam, and in Figs. 3 and 4 for the column. In both cases, the load ratio of variable actions $k=0$, which proves to be more critical than $k>0$, as shown in [9].

The resulting reliability levels shown in Figs. 1 to 4 should be considered only as indicative and relative values that are obviously dependent on assumed characteristics of basic variables shown in Table 2. Particularly the model uncertainties $K_{R}$ and $K_{E}$ have significant effects. Characteristics of these variables are chosen taking into account available data provided by JCSS [12], where the mean 1.20 (greater than 1.10 given in Table 2 for $K_{R}$ ) and the coefficient of variation 0.15 (the same as given in Table 2) are indicated. Note that if

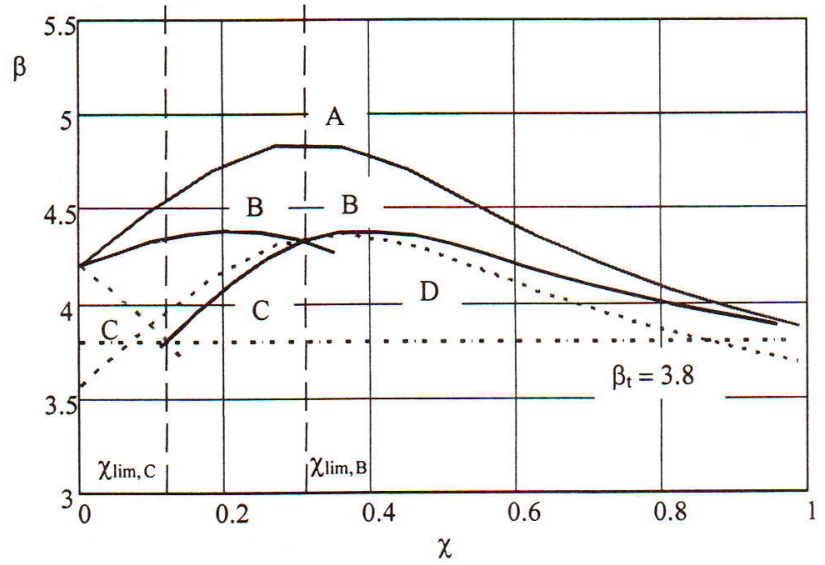

Fig. 1: Reliability index $\beta$ for the reinforced concrete beam versus the load ratios $\chi$ for reinforcement ratio $\rho=0,01$ and $k=0$; A, B, C - alternative combinations according to EN 1990 $\left(\gamma_{G}=1.35, \gamma_{Q}=1.5\right), \mathrm{D}-$ combination $\mathrm{A}$ with reduced partial factors $\left(\gamma_{G}=1.2, \gamma_{Q}=1.4\right)$.

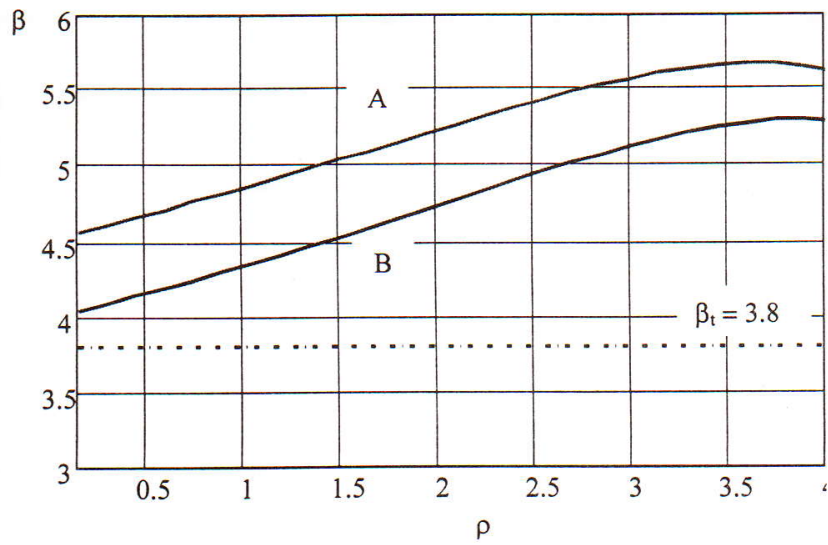

Fig. 2: Reliability index $\beta$ for the reinforced concrete beam versus reinforcement ratio $\rho$ for ratios $\chi=0.3$ and $k=0 ; \mathrm{A}, \mathrm{B}-$ alternative combination according to EN 1990 [1] $\left(\gamma_{G}=1.35, \gamma_{Q}=1.5\right)$. the mean 1.20 is used instead of 1.10 , the reliability level would increase considerably (reliability index $\beta$ would increase by about 0.5 ).

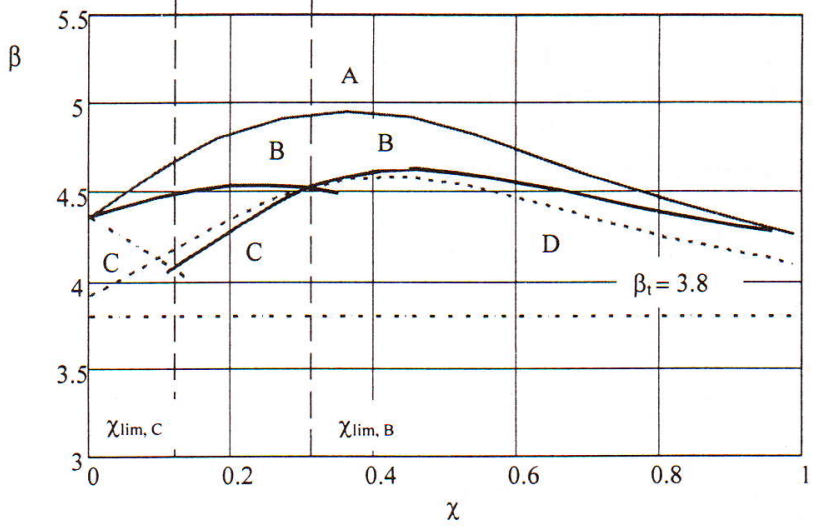

Fig. 3: Reliability index $\beta$ for the reinforced concrete column versus the load ratios $\chi$ for reinforcement ratio $\rho=0.04$ and $k=0 ; \mathrm{A}, \mathrm{B}, \mathrm{C}-$ alternative combinations according to EN $1990[1]\left(\gamma_{G}=1.35, \gamma_{Q}=1.5\right), \mathrm{D}-$ combination A with reduced partial factors $\left(\gamma_{G}=1.2, \gamma_{Q}=1.4\right)$.

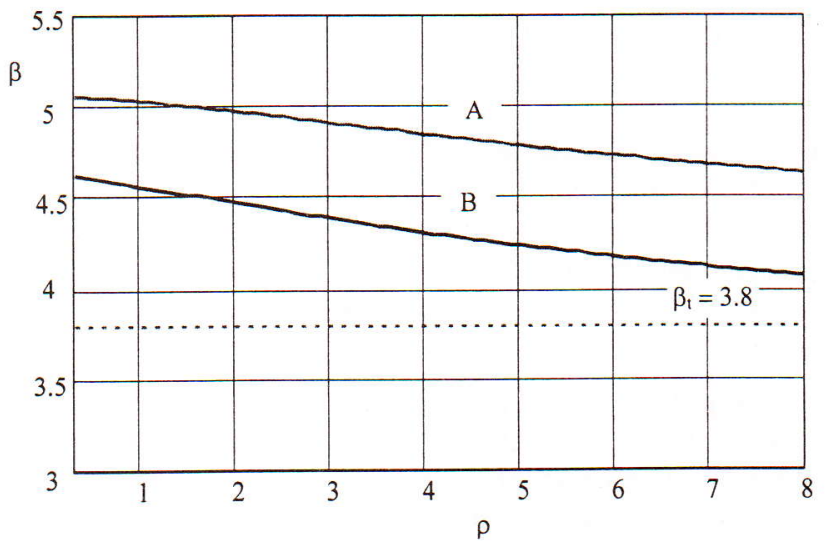

Fig. 4: Reliability index $\beta$ for the reinforced concrete column versus reinforcement ratio $\rho$ for $\chi=0.3$ and $k=0 ; \mathrm{A}, \mathrm{B},-$ alternative combination according to $\mathrm{EN} 1990$ [1] $\left(\gamma_{G}=1.35, \gamma_{Q}=1.5\right)$.

Another important aspect of the obtained results is the dependence of the reliability of reinforced concrete elements on their reinforcement ratio $\rho$. As indicated in Figs. 2 and 4, the reliability of the beam (Fig. 2) increases with increasing reinforcement ratio $\rho$ (reliability index $\beta$ may easily increase by about 1), the reliability of the column (Fig. 4) decreases with increasing reinforcement ratio $\rho$ (reliability index $\beta$ may decrease by about 0.5 ). For this reason the reinforcement ratio $\rho=0.01$ is considered for the beam in Fig. 1, and $\rho=0.04$ is considered for the column in Fig. 3.

Figures 1 and 3 show that the reliability level of both the beam and the column determined for load combination $\mathrm{A}$ is greater than the reliability resulting from load combinations $\mathrm{B}, \mathrm{C}$ and $\mathrm{D}$. The lowest reliability level is provided by load combination C, allowed in EN 1990 [1], and by load combination $\mathrm{D}$ when reduced partial factors for actions are applied $\left(\gamma_{G}=1.2, \gamma_{Q}=1.4\right.$ instead of $\left.\gamma_{G}=1.35, \gamma_{Q}=1.5\right)$. A comparison of Figs. 1 and 2 further indicates that the reliability level of the beam (Fig. 1) is slightly lower than the 
reliability level of the column (Fig. 2). Reliability index $\beta$ for the beam may be lower (by about 0.3 ) than $\beta$ for the column. This finding is however strongly dependent on the model uncertainties $K_{\mathrm{R}}$ and $K_{\mathrm{E}}$, and should not be generalised.

For both the beam and the column the load combinations $\mathrm{C}$ and $\mathrm{D}$ lead to reliability approaching the level recommended in EN $1990\left(\beta_{\mathrm{t}}=3.8\right)$, in particular for very low load ratios $\chi$ (when the permanent load is dominant) and for load ratios $\chi$ greater than 0.6 (when the imposed load is more significant than the permanent load). Alternative $B$ provides the most uniform reliability level within the expected load ratios $\chi$ (a realistic range of $\chi$ is from 0.1 to 0.6 ) and from this point of view seems to provide the best load combination.

\section{Concluding remarks}

The newly available EN 1990 provides alternative design procedures and parameters that should be unambiguously specified in the National annexes of Member States of CEN. These alternative design procedures lead in some cases to significantly different reliability levels. Preparation of National annexes is therefore a complicated task for each Member State. Furthermore, the Eurocode standards recognise the responsibility of the regulatory authorities in each Member State and safeguard their right to determine values related to regulatory safety matters at national level.

Simple examples of reinforced concrete elements confirm the results of the earlier studies that the reliability of structures, designed according to the alternative combination rules provided in EN 1990 by expressions (6.10), (6.10a) and (6.10b) may vary considerably. Expression (6.10) leads to the most reliable but in some cases to uneconomical structures. Twin expressions (6.10a) and (6.10b) provide a lower but comparatively most uniform reliability level for all load ratios. Moreover, they seem to fully comply with EN recommendations (reliability index 3,8 for a 50-year time period). The lowest reliability is obtained from the third alternative, given by modified expression (6.10a) and expression (6.10b). This alternative seems to lead to a rather low reliability level, particularly for structures exposed mainly to a permanent load.

An important aspect of reliability of reinforced concrete elements is the reinforcement ratio $\rho$. It appears that the reliability of the beam increases considerably with increasing reinforcement ratio $\rho$ (reliability index $\beta$ may easily increase by about 1), the reliability of the column decreases with increasing reinforcement ratio $\rho$ (reliability index $\beta$ may decrease by about 0.5 ).

In order to make an unambiguous recommendation for National annexes to EN 1990, further investigations are urgently needed. Obviously more complicated structural elements, made of various materials, should be analysed and compared. Such a calibration activity should preferably be organised on an international level. The short-term objective of these activities should be to develop the necessary background materials for preparation of the National annexes. The long-term objective should be to further harmonise the alternative design procedures to be considered during the next revision of the present generation of Eurocodes.

\section{Acknowledgement}

This study has been partly prepared at the Klokner Institute of the CTU in Prague, Czech Republic as a part of the research project CEZ: J04/98:210000029 "Risk Engineering and Reliability of Technical Systems" supported by MSMT.

\section{References}

[1] EN 1990: 2002 Eurocode - Basis of Structural Design. European Committee for Standardisation, April 2002, p. 87.

[2] EN 1991-1-1: 2002 Eurocode 1: Actions on Structures Part 1-1: General Actions - Densities, Self-weight, and Imposed Loads for Buildings. European Committee for Standardisation, April 2002, p. 46.

[3] ENV 1991-1: Basis of Design and Actions on Structures. Part 1: Basis of Design. European Committee for Standardization, 1994.

[4] ENV 1991-2-1: Actions on Structures - Part 2-1: General Actions - Densities, Self-weight and Imposed Loads. European Committee for Standardization, 1995.

[5] prEN 1992-1-1: Design of Concrete Structures. General Rules and Rules for Buildings. CEN/TC 250/SC2, Draft for Stage 49, July 2002, p. 46.

[6] ENV 1992-1-1: Design of Concrete Structures. General Rules and Rules for Buildings. European Committee for Standardization, 1993, p. 46.

[7] SAKO; Joint Committee of NKB and INSTA-B. Basis of Design of Structures. Proposal for Modification of Partial Safety Factors in Eurocodes. 1999, p. 55.

[8] Holický, M., Marková, J.: Verification of Load Factors for Concrete Components by Reliability and Optimization Analysis: Background Documents for Implementing Eurocodes. Progress in Structural Engineering and Materials, Vol. 2, 2000, No. 4, p. 502-507.

[9] Gulvanessian, H., Holický, M., Marková, J.: Calibration of Eurocode Reliability Elements Considering Steel Members. In: Proceedings of Third European Conference on Steel Structures, Volume II; Antonio Lamas and Luis Simoes da Silva, CMM - Associacao Portuguesa de Construcao Metalica e Mista, Guimaraes (Portugal), ISBN 972-98376-3-5, p. 1511-1520.

[10] VaP, Variable Processor, version 1.6, ETH Zürich, 1997.

[11] COMREL, version 7.10, Reliability Consulting Programs, RCP MUNICH, 1999.

[12] JCSS, Joint Committee for Structural Safety, http://www.jcss.ethz.ch/, 2002.

Prof. Ing. Holický Milan, DrSc.

Phone: +420224353842

Fax: +420224355232

e-mail: holicky@klok.cvut.cz

Ing. Marková Jana, Ph.D.

Department of Reliability

Czech Technical University in Prague,

Klokner Institute

Šolínova 7

16608 Prague 6, Czech Republic 